\title{
RESILIENCE AND EMERGENCY MANAGEMENT OF ROAD TUNNELS: THE CASE STUDY OF THE SAN ROCCO AND STONIO TUNNELS IN ITALY
}

\author{
FABIO BORGHETTI ${ }^{1}$, ALESSIO FRASSOLDATI ${ }^{2}$, MARCO DERUDI $^{2}$, \\ IGINO LAI $^{3}$ \& CRISTIAN TRINCHINI ${ }^{3}$ \\ ${ }^{1}$ Design Department, Mobility and Transport Laboratory, Politecnico di Milano, Italy \\ ${ }^{2}$ Department of Chemistry, Materials and Chemical Engineering, Politecnico di Milano, Italy \\ ${ }^{3}$ Strada dei Parchi S.p.A, Italy
}

\begin{abstract}
In Italy, mainly due to its complex orography, there are more than $50 \%$ of road tunnels longer than $500 \mathrm{~m}$ belonging to the Trans European Road Network. Moreover, many road tunnels were designed and built several years ago, where both traffic flows and vehicle sizes were different. Generally speaking, it is possible to state that if on one hand road tunnels allow the improvement of the planoaltimetric coordination of road layouts, on the other hand they can represent a safety problem for users and for the infrastructure in case of a major event. With this in mind, it is interesting to study the resilience of a road tunnel following an event: how can the resilience of a tunnel be increased by considering emergency management? How can negative consequences be reduced by adopting specific safety measures, such as emergency teams? Starting from these two questions, the main goal of this work was to analyze two fire events that occurred in two tunnels located on the A24 highway in Italy between 2019 and 2021 and managed by Strada dei Parchi S.p.A. Both fires involved a light vehicle and there were no injuries or fatalities. For each of the two events, the response time of the emergency teams and the resolution time of the event were analyzed. In the first case it is possible to evaluate the effectiveness of the emergency teams in controlling and/or extinguishing a fire, while in the second case the impact on road traffic caused by the tunnel closure is analyzed. These analyses can be used for two important purposes: (i) risk assessment of a tunnel considering the emergency team as a safety measure; and (ii) implementation of traffic management plans to define the best strategy to be adopted according to the estimated time of closure of a tunnel.

Keywords: road tunnel, tunnel safety, emergency management, traffic management, transport resilience, tunnel resilience, tunnel operations, emergency teams effectiveness, tunnel fire, tunnel accident.
\end{abstract}

\section{INTRODUCTION}

In Italy, mainly due to its complex orography, there are more than $50 \%$ of road tunnels longer than $500 \mathrm{~m}$ belonging to the Trans European Road Network (TERN) [1], [2]. Moreover, many road tunnels, were designed and built several years ago, where both traffic flows and vehicle sizes were different. The use of road tunnels makes it possible to guarantee the mobility of people and goods, limiting, for example, the tortuosity, the slope and length of roadways, and fuel consumption; this leads to a reduction of potential danger factors. Generally speaking, it is possible to state that if on one hand road tunnels allow the improvement of the plano-altimetric coordination of road layouts, on the other hand they can represent a safety problem for users and for the infrastructure in case of a major event. This is true not only for tunnels located in suburban areas but also for urban ones: today tunnels play an important role, as they allow the reorganization of traffic in the city and therefore the rethinking of city spaces, making them more human-scale [3]. After the fire that occurred in the Mont Blanc tunnel in 1999, which caused 39 deaths and extensive damage to the infrastructure (almost 3 years of closure), the European Community issued Directive 2004/54/EC on minimum safety requirements for tunnels belonging to the TERN of more 
than $500 \mathrm{~m}$ in length. Thanks to this Directive, a normative framework has been implemented that today includes technical regulations and guidelines on good standards for the design, construction and operation of road tunnels [4]. Due to the serious consequences and deaths caused also by the events that occurred in other European tunnels (Gotthard in 2001, Tauri in 2002 and Fréjus in 2005), public and political awareness of the problem has increased: specifically, the importance of this type of infrastructure on a human, cultural, economic and social level has been highlighted. Specifically, the 2004 European Directive regulates tunnel safety by establishing minimum safety requirements in terms of equipment, infrastructure and management procedures, and by identifying risk analysis as an analytical and welldefined methodology for estimating the risk level of each tunnel. In practice, the Directive regulates safety:

- identifying the tasks of the entities and administrative authorities responsible for the management and control of tunnels;

- establishing minimum requirements for equipment and infrastructure based on certain parameters (e.g., tunnel length and traffic volumes);

- identifying and recommending Risk Analysis as the appropriate analytical methodology to determine the level of risk of each tunnel.

With reference to this last issue, the main goal of the quantitative risk analysis (QRA) for road tunnels is to assess the risk for the specific "tunnel system" as illustrated in Fig. 1.

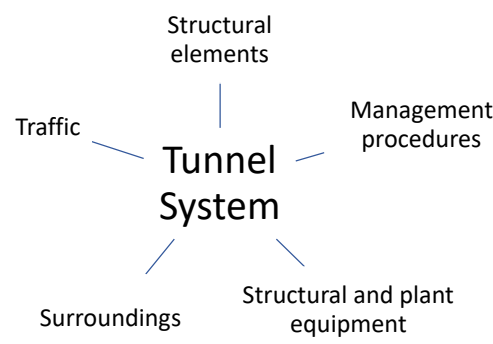

Figure 1: Tunnel system components.

The analysis includes consideration of several parameters such as accident rate, traffic, tunnel geometry, structures/equipment, infrastructure and management measures. Among the different steps of the risk analysis there is the estimation of the frequencies of possible accidental events, which has to consider: (i) the type of vehicles involved (light and/or heavy); (ii) the location of the accident inside the tunnel; and (iii) the number of injuries and/or fatalities. One possible technique, based on event tree analysis, is to define top event, and then assess the frequencies and consequences of each accidental scenario [5], [6]. In this regard, emergency teams can influence the evolution of an accidental scenario, both in terms of the frequency of occurrence and the consequences of the event itself. In the first case, emergency teams can control or extinguish a fire while preventing the fire from involving other vehicles; in the second case, they can help and coordinate the evacuation of users from the tunnel [7], [8]. In general, the probability of occurrence of an accident and the probability of being injured is lower in tunnels than in open road sections. It should be noted, however, that if an accident (e.g., fire) occurs in a tunnel, the potential consequences inside this confined environment are significantly greater than in open sections [9], [10]. Vehicle drivers 
are more careful driving in tunnels than in open sections: as a result, the crash risk is estimated to be about half that of open sections [11]-[13]. Because of this aspect, safety studies and risk analyses for road tunnels typically consider as reference accidental scenarios vehicle fires and dangerous goods releases, which can cause major consequences [9], [14]-[16]. Prolonged closure of a tunnel following an event can also result in socio-economic impacts that can be observed across a large area (region or country): such a situation can cause increased costs to the community. More specifically, these impacts can be related to the loss (or reduction) of freight and passenger traffic (including tourism) and increased travel time caused by the detour of traffic to alternative routes. In some studies, the risk assessment is done by also considering the decision-making process from an economic perspective [17]. With this in mind, it is interesting to study the resilience of a road tunnel following an event: how can the resilience of a tunnel be evaluated and increased by considering emergency management? How can negative consequences and effects be reduced by adopting specific safety measures, such as emergency teams? Starting from these two questions, the main goal of this work was to analyze two fire events that occurred in two tunnels located on the A24 highway in Italy between 2019 and 2021 and managed by Strada dei Parchi S.p.A. Both fires involved a light vehicle and there were no injuries or fatalities. For each of the two events, the response time of the emergency teams and the resolution time of the event were analyzed. In the first case it was possible to evaluate the effectiveness of the emergency teams in controlling and/or extinguishing a fire, while in the second case the impact on road traffic caused by the tunnel closure (resilience) was analyzed. These analyses can be used for two important purposes: (i) risk assessment of a tunnel considering the emergency team as a safety measure; and (ii) implementation of traffic management plans to define the best strategy to be adopted according to the estimated time of closure of a tunnel.

\section{RESILIENCE AND EMERGENCY MANAGEMENT}

Highway accident and emergency management professionals are continually working to improve strategies to ensure safe and rapid incident clearance [18]. When an event occurs, several activities need to be executed including protecting the crash site by realizing detours or implementing other traffic management measures when necessary, such as rescuing stopped traffic, and rescuing and evacuating injured people. In the event of long road closures, domino effects can occur that result in high levels of congestion in the surrounding road network, so it is important to alert drivers about the road/tunnel closures as soon as possible so that they can take alternative routes and avoid being trapped and increasing congestion in the area where the event occurred. When an accident occurs, it is difficult to estimate the cost of delays due to accident consequences, because generally speaking, not only the loss of time must be taken into account, but also, for example, late freight deliveries, missed appointments, missed flights at airports, personal inconvenience, and frustration. From an analytical point of view, the various factors that can most affect the response time due to an accident are: location, time of day, direction of travel, accident type, weather conditions, number and type of vehicles involved, number and location of lanes involved, number and type of responders required on scene, traffic queues (delay). In the scientific literature, several studies have addressed the issue of resilience of a transportation infrastructure following a major event [19], [20]. To date, there are several definitions of resilience; one of which can be "the ability of an entity, e.g., asset, organization, community, region - to anticipate, withstand, absorb, respond to, adapt to, and recover from a disruption" [21]. When a roadway accident occurs, including those in tunnels, the recovery time should be considered, which could be longer than that of a common accident due to the confined space. Fig. 2 shows the trend and components of resilience with reference to a transportation 
system following a major event. The performance of a transportation system could be evaluated by considering the satisfied transportation demand (e.g., percentage of traffic satisfied).

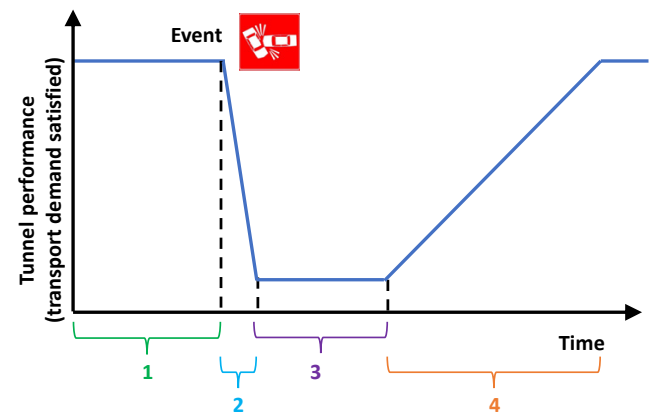

\begin{tabular}{|c|c|c|c|}
\hline 1 & 2 & 3 & 4 \\
\hline Preparedness & Mitigation & Response & Recovery \\
\hline $\begin{array}{l}\text { Activities } \\
\text { taken by an } \\
\text { entity to } \\
\text { define the } \\
\text { hazard } \\
\text { environment } \\
\text { to which it is } \\
\text { subject }\end{array}$ & $\begin{array}{l}\text { Activities taken } \\
\text { prior to an } \\
\text { event to reduce } \\
\text { the severity or } \\
\text { consequences } \\
\text { of an hazard }\end{array}$ & $\begin{array}{l}\text { Immediate and } \\
\text { ongoing } \\
\text { activities, tasks } \\
\text { programs and } \\
\text { systems that } \\
\text { have been } \\
\text { undertaken or } \\
\text { developed to } \\
\text { manage the } \\
\text { adverse effects } \\
\text { of an event }\end{array}$ & $\begin{array}{l}\text { Activities and } \\
\text { programs } \\
\text { designed to } \\
\text { effectively } \\
\text { and } \\
\text { efficiently } \\
\text { return } \\
\text { conditions to } \\
\text { a level that is } \\
\text { acceptable to } \\
\text { the entity }\end{array}$ \\
\hline
\end{tabular}

Figure 2: Resilience components of a transport system. (Source: Adapted from [21]-[23].)

A number of international studies have confirmed that the presence of firefighting crews or emergency teams located near tunnel entrances (capable of rapid response) brings significant benefits in terms of effectiveness in managing a tunnel fire [5], [24]. A study performed on some Japanese and European tunnels states that firefighting team intervention should occur within 7 min [25]. In the report "Fire Safe Design, Technical Report - Part 3" [26], it is stated that the intervention of emergency teams is effective if it occurs within the first $10 \mathrm{~min}$ of the accidental event. An additional aspect relates to the emergency teams' situational awareness to effectively execute their operations. To ensure this, it is necessary that teams are dedicated to a specific tunnel and specific communication systems are used with the control center, which oversees the evolution of the accidental scenario. The added value in using emergency teams, in addition to their speed of intervention, is their detailed knowledge of the tunnel system with particular reference to infrastructure measures, equipment and management procedures. In this way, emergency teams are able to operate to control or extinguish fire principles before they evolve into larger fires [5]. Moreover, as abovementioned, emergency teams can support tunnel users in their evacuation process by quickly providing useful information about the direction of the closest emergency exit to be reached [26]. In case of relevant events, thanks to the specific knowledge of the tunnel system, these teams can eventually support the intervention of other rescue teams (e.g., fire brigade) by providing detailed information about the evolution of the scenario and the infrastructure also through a continuous communication with the control center [5], [27], [28]. In another research, several tunnel fires were analyzed to estimate the response time and effectiveness of teams in controlling or extinguishing the fire. The study also analyzed the intervention strategies of fire teams for different types of tunnels (e.g., one-way or twoway, with or without vehicle queues in the smoke zone, and different ventilation strategies) [24]. When a major event occurs and it requires the prolonged closure of a tunnel, alternative routes can reduce traffic demand on the roadway and prevent users from approaching the accident area. Identifying practicable alternative routes is not always easy; this task requires the implementation of specific traffic management plans. However, not all alternative routes may be suitable for all types of vehicles. As an example, for heavy vehicles, there may be restrictions related to mass and shape limits that could restrict passage on certain routes (e.g., presence of a bridge or bottleneck). In these cases, separate alternative routes may be 
identified for light and heavy vehicles. The analysis of alternative routes and more general traffic management measures also depend on the traffic flows affected by an event. Assuming that the average daily traffic (ADT) of a road is known, it is possible to represent its trend as a function of time during the 24 hours as shown in Fig. 3. The duration of an accident event may lead to a reduction or even an interruption of traffic depending on the scenario and the type of infrastructure. In this way, it is possible to estimate how many vehicles will potentially be involved and will need to be managed (e.g., on alternative routes or stopped at suitable service areas) depending on the period in which the event occurs (e.g., peak hour). Fig. 3 also shows the timeline for the different management activities from the time an accident occurs until vehicle traffic is recovered.

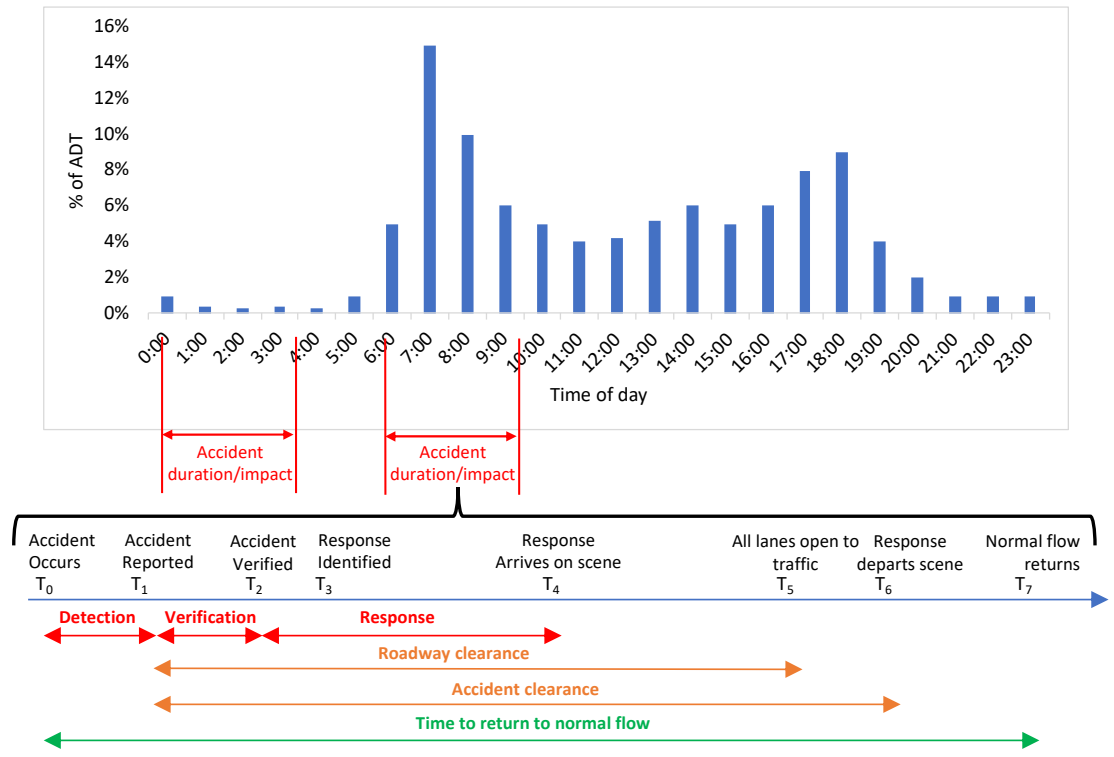

Figure 3: Qualitative trend of average daily traffic and timeline of traffic accident elements. (Source: Adapted from [29].)

\section{CASE STUDY: THE TUNNELS OF THE A24 AND A25 HIGHWAYS IN ITALY}

The A24 and A25 highways form a freeway system in Italy currently managed by Strada dei Parchi S.p.A, which starts in Rome and ends in Teramo (A24). About halfway along the route, at Torano, there is a junction that allows to go towards Pescara (A25). The two highways have a total length of about $280 \mathrm{~km}(\sim 165 \mathrm{~km}$ of A24 from Rome to Teramo and $\sim 115 \mathrm{~km}$ of A25 from Torano to Pescara). The route is characterized by the presence of Apennines: it follows that there are numerous bridges, viaducts and tunnels. Specifically, on the two highways there are 153 long bridges and viaducts for a total length of $118.8 \mathrm{~km}$. In addition, there are 54 tunnels for a total length of $70.8 \mathrm{~km}$, which corresponds to $12.6 \%$ of the entire route. 14 tunnels have a length greater than $500 \mathrm{~m}$ and belong to the TERN network: eight of these tunnels exceed 2,000 m and one exceeds 10,000 m (Gran Sasso tunnel). Fig. 4 shows the layout of the A24 and A25 highways and the location of the 14 tunnels longer than $500 \mathrm{~m}$. Twelve tunnels are located on the A24 highway (highlighted using blue dashed line) 
while two tunnels are located on the A25 highway (green dashed line). The two highways consist of two carriageways and each carriageway has two lanes in each direction plus an emergency lane (not present inside the tunnels). Table 1 summarizes the main features of the two tunnels analyzed: San Rocco and Stonio.

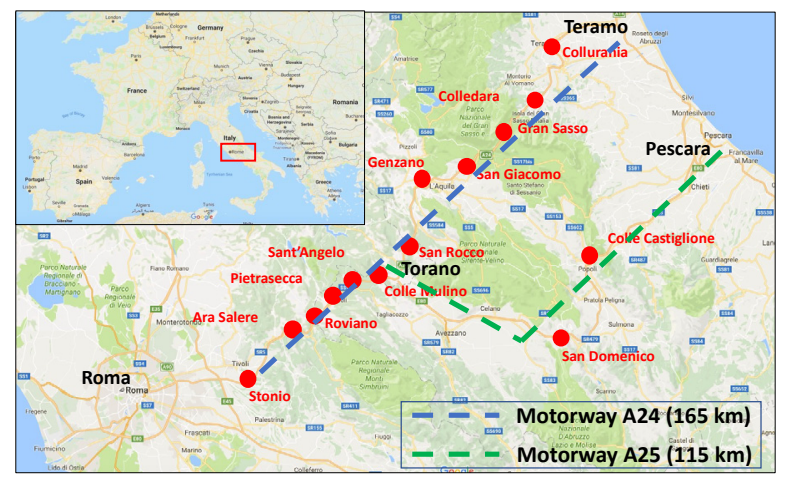

Figure 4: Location of the 14 tunnels managed by Strada dei Parchi S.p.A. (Source: Strada dei Parchi S.p.A.)

Table 1: Main features of the San Rocco tunnel and Stonio tunnel. (Source: Strada dei Parchi S.p.A.)

\begin{tabular}{|l|c|c|c|c|}
\hline & \multicolumn{2}{|c|}{ San Rocco tunnel } & \multicolumn{2}{c|}{ Stonio tunnel } \\
\hline Feature & Right tube & Left tube & Right tube & Left tube \\
\hline Year of opening to traffic & 1969 & 1969 & 1969 & 1969 \\
\hline One-way tunnel (yes/no) & Yes & Yes & Yes & Yes \\
\hline Length (m) & 4181 & 4176 & 1242 & 1192 \\
\hline Cross-section area $\left(\mathrm{m}^{2}\right)$ & 70 & 70 & 54 & 54 \\
\hline Central height $(\mathrm{m})$ & 8.5 & 8.5 & 6.5 & 6.5 \\
\hline Available height $(\mathrm{m})$ & 5 & 5 & 5 & 5 \\
\hline Lane width $(\mathrm{m})$ & 3.75 & 3.75 & 3.75 & 3.75 \\
\hline Overtaking lane width (m) & 3.75 & 3.75 & 3.75 & 3.75 \\
\hline Number of lanes & 2 & 2 & 2 & 2 \\
\hline Emergency lane (yes/no) & No & No & No & No \\
\hline Average longitudinal slope $(\%)$ & $2.2 \%$ & $-2.2 \%$ & $2.6 \%$ & $-2.6 \%$ \\
\hline Minimum bending radius $(\mathrm{m})$ & 1200 & 1200 & 1010 & 1010 \\
\hline Average daily traffic $($ vehicle/day) & 7122 & 6992 & 15398 & 15176 \\
\hline Light vehicles (LV) $(\%)$ & 86 & 87 & 88 & 88 \\
\hline Heavy goods vehicles (HGV) $(\%)$ & 14 & 13 & 12 & 12 \\
\hline Speed limit (km/h) & 110 & 110 & 110 & 110 \\
\hline $\begin{array}{l}\text { Overtaking heavy vehicles }(>3.5 \mathrm{t}) \\
\text { (yes/no) }\end{array}$ & No & No & No & No \\
\hline Dangerous goods transport & Yes & Yes & Yes & Yes \\
\hline
\end{tabular}




\subsection{Emergency teams description}

One of the safety measures adopted by Strada dei Parchi S.p.A. concerns the emergency teams located along the A24 and A25 highways near the tunnels. The firefighting service consists of emergency teams with special vehicles and equipment to control and extinguish fires. The personnel have specific qualifications such as, for example, that of "Emergency and first aid workers in tunnels/confined areas". The proximity of the emergency teams to the tunnels allows them to quickly reach the scene of the accidental event and to control/suppress a possible fire. In addition, team personnel can support tunnel users during the evacuation process. Both vehicles are equipped with an emergency firefighting system using micronized water. Fig. 5 shows the main technical features and Fig. 6 shows an example of location of emergency teams near a tunnel.

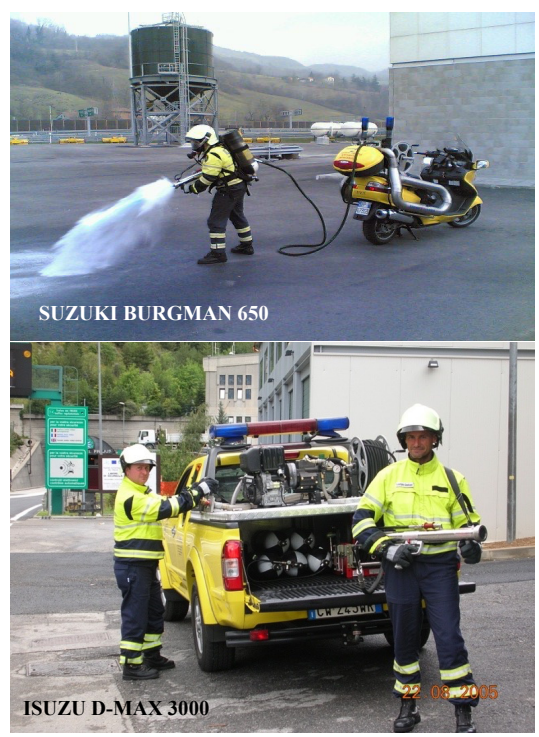

\begin{tabular}{|l|}
\hline Description \\
\hline $\begin{array}{l}\text { 1 stainless steel tank with a capacity of about } 60 \mathrm{~L} \\
\text { of extinguishing liquid }\end{array}$ \\
\hline 2 compressed air cylinders of $9 \mathrm{~L}$ each at $300 \mathrm{bar}$ \\
\hline 1 fire hose with a length of about $40 \mathrm{~m}$ \\
\hline 1 spray gun of $1 \mathrm{~L}$ \\
\hline
\end{tabular}

\section{Description}

1 stainless steel tank with a capacity of about $400 \mathrm{~L}$ of extinguishing liquid

5 compressed air cylinders of $9 \mathrm{~L}$ each at 300 bar

1 fire hose with a length of about $40 \mathrm{~m}$

1 spray gun of $1 \mathrm{~L}$

1 high pressure pump

1 fractional Water Lance

Figure 5: Main technical characteristics of vehicles used by firefighting teams. (Source: Strada dei Parchi S.p.A.)

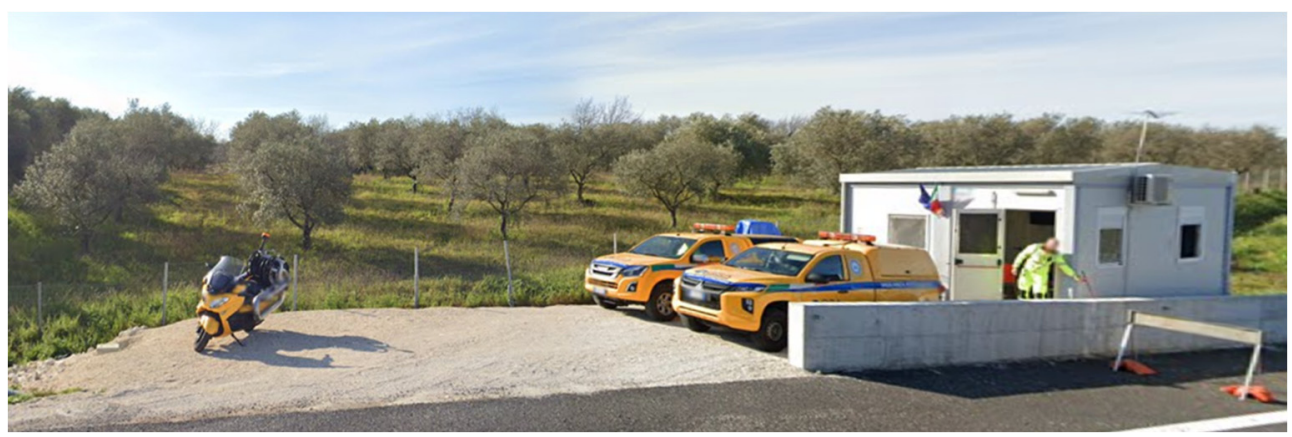

Figure 6: Example of location of emergency teams near a tunnel. (Source: https://www.google.it/maps/.) 


\subsection{San Rocco tunnel event}

On 23 February 2021, a light vehicle fire occurred within the right tube of the San Rocco tunnel, which is $4,181 \mathrm{~m}$ long. The possible cause of the fire is associated with an engine failure. Fortunately, there were no injuries or fatalities. Damage to infrastructure and equipment was also minor. Fig. 7 shows the representation of the event within the tunnel and the location of the emergency teams about $450 \mathrm{~m}$ away from the tunnel entrance. Fig. 8 shows two pictures of the involved vehicle after the fire.

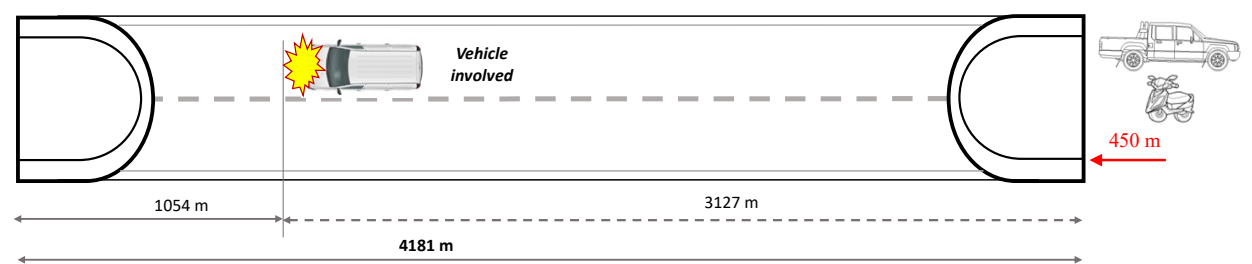

Figure 7: Graphical representation of the event inside the San Rocco tube. (Source: Strada dei Parchi S.p.A.)

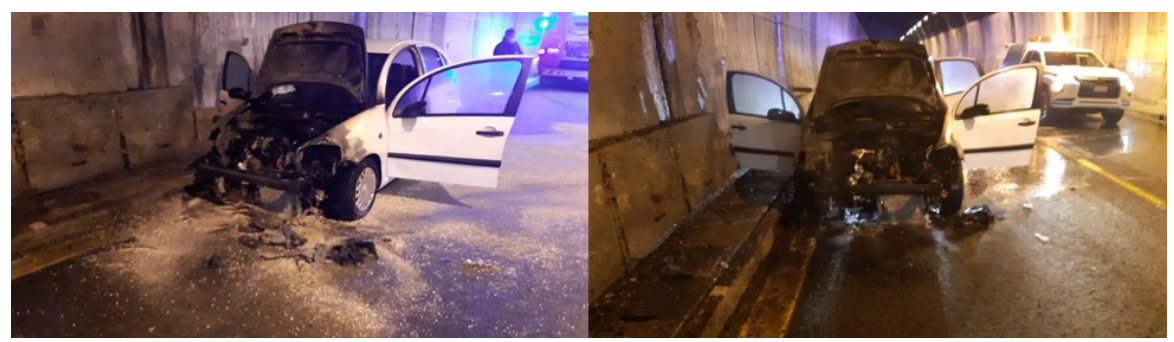

Figure 8: Vehicle involved in the event inside the San Rocco tunnel. (Source: Strada dei Parchi S.p.A.)

The event occurred at 12:23 and as soon as it was detected the emergency team was activated. The tunnel is equipped with AID (Automatic Incident Detection) cameras that allow to quickly detect an event and communicate it to the control center and emergency teams. The emergency team arrived at the location of the event in approximately 2 min $(12: 25)$ and took approximately 15 min to extinguish the fire and secure the vehicle (12:40). It then took approximately $34 \mathrm{~min}$ to remove the vehicle, perform authority surveys, clean the roadway, and reopen the two lanes to traffic (13:14). Fig. 9 shows the timeline of this accident and highlights the transport demand not satisfied (TDNS) area (in gray).

Regarding the impact of the event on road traffic, it is necessary to consider the total duration of the event (about $51 \mathrm{~min}$ ) and the ADT (7,122 vehicles per hour). Considering eqn (1) it is possible to estimate the unsatisfied transport demand which results to be of 6054 vehicles:

$$
\text { TDNS }=\text { ADT } \times \text { event duration }=7,122 \frac{\text { vehicles }}{\text { hours }} \times 0.85 \mathrm{~h}=6,054 \text { vehicles. }
$$

It follows that this value $(6,054)$ represents the number of vehicles that will be stopped in the queue and need to be managed during the tunnel closure (impact). 


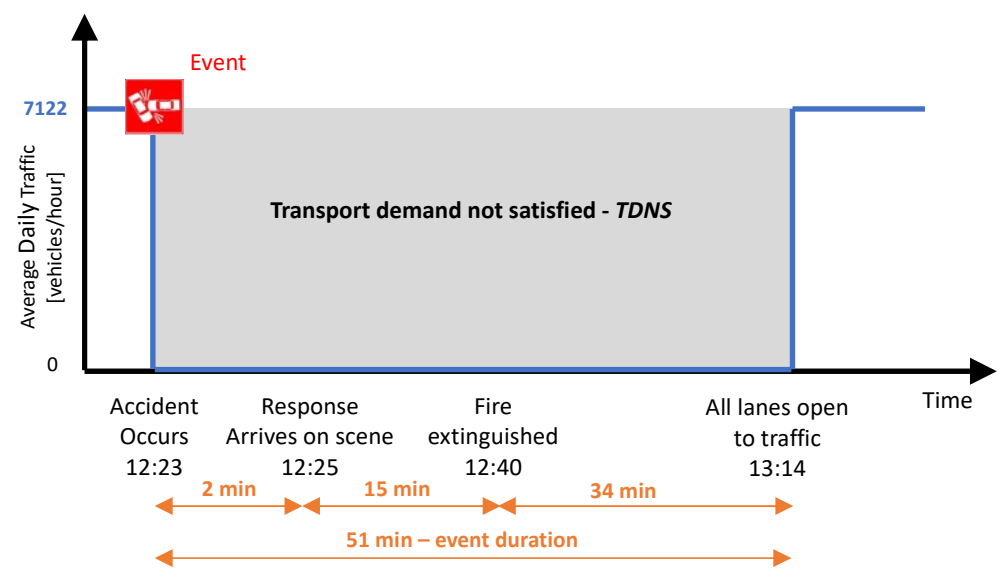

Figure 9: Timeline of traffic accident elements inside the San Rocco tunnel.

\subsection{Stonio tunnel event}

On 22 June 2019, a light vehicle fire occurred within the right arch of the Stonio tunnel, which is 1,242 m long. Again, the possible cause of the fire is associated with an engine failure. Damage to infrastructure and equipment was also minor. Fig. 10 shows the representation of the event within the tunnel and the location of the emergency teams about $400 \mathrm{~m}$ away from the tunnel entrance. Fig. 11 shows two pictures of the involved vehicle after the fire.

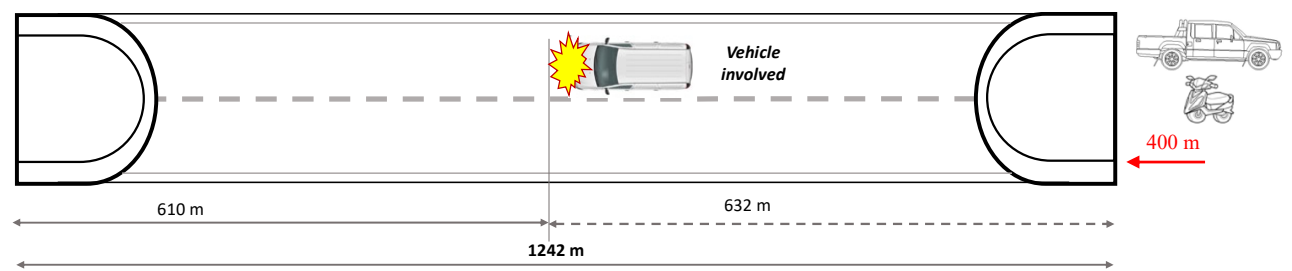

Figure 10: Graphical representation of the event inside the Stonio tube. (Source: Strada dei Parchi S.p.A.)

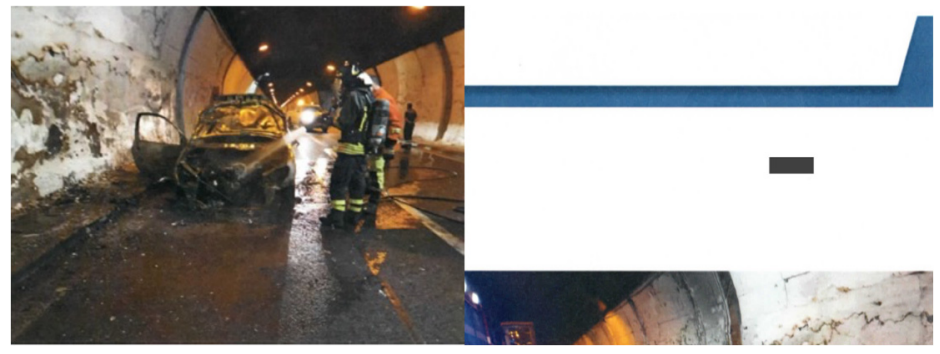

Figure 11: Vehicle involved in the event inside the Stonio tunnel. (Source: Strada dei Parchi S.p.A.) 
A timeline of the Stonio tunnel event is shown in Fig. 12. The event occurred at 20:43 and after about 3 min (20:46) the emergency team was activated. The emergency team arrived at the scene of the event in about $2 \mathrm{~min}(20: 48)$ and took about $6 \mathrm{~min}$ to extinguish the fire and secure the vehicle (20:54). It then took approximately $45 \mathrm{~min}$ to remove the vehicle, conduct surveys by authorities, clean the roadway, and reopen the two lanes to traffic (at about 21:39).

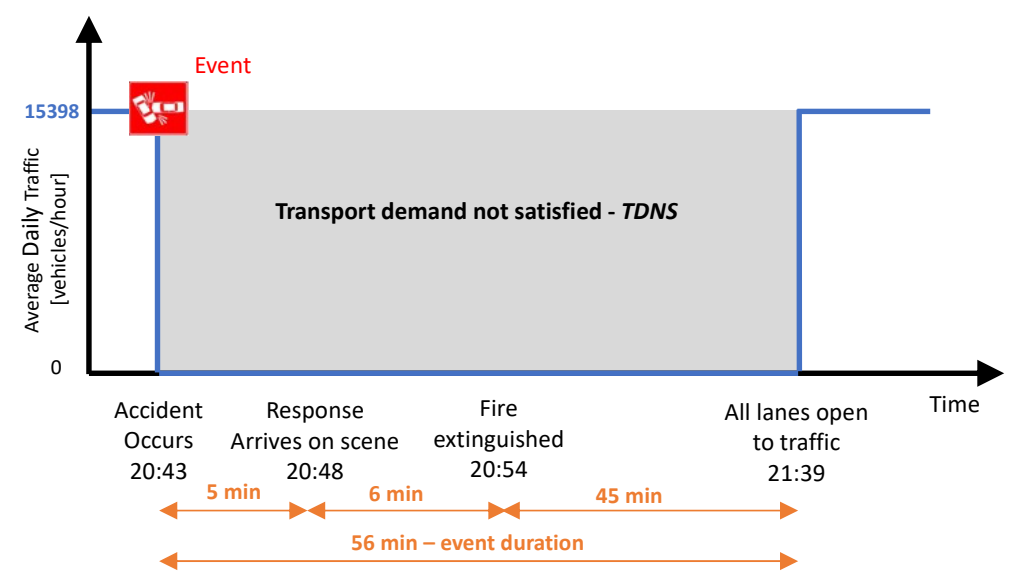

Figure 12: Timeline of traffic accident elements inside the Stonio tunnel.

Also in this second event, as far as the impact on vehicle traffic is concerned, it is necessary to consider the total duration of the event equal to about $56 \mathrm{~min}$ and the ADT $(15,398$ vehicles per hour). By means of eqn (2) it is possible to estimate the unsatisfied transport demand which is 14371 vehicles:

$$
\text { TDNS }=\text { ADT } \times \text { event duration }=15,398 \frac{\text { vehicles }}{\text { hours }} \times 0.93 \mathrm{~h}=14,371 \text { vehicles. }
$$

The light vehicle fire in the Stonio tunnel resulted in a traffic disruption: approximately 14371 vehicles were stopped in the queue and had to be handled during the tunnel closure (impact).

\section{CONCLUSIONS}

The main goal of this work was to analyze two fire events that occurred in two tunnels located on the A24 highway in Italy between 2019 and 2021 and managed by Strada dei Parchi S.p.A. Both fires involved a light vehicle and there were no injuries or fatalities. For each of the two events, the response time of the emergency teams and the resolution time of the event were analyzed. The effectiveness of the emergency teams in controlling and/or extinguishing a fire, and impact on road traffic caused by the tunnel closure were analysed for the two cases. These analyses can be used for two important purposes: (i) risk assessment of a tunnel considering the emergency team as a safety measure; and (ii) implementation of traffic management plans to define the best strategy to be adopted according to the estimated time of closure of a tunnel. Both events analyzed involved a light vehicle. From a quantitative point of view in the event that occurred in the San Rocco tunnel, fire crews intervened in $2 \mathrm{~min}$ and the total event lasted about $51 \mathrm{~min}$. The closure of the tunnel resulted in an impact that can be estimated at about 6,054 vehicles to be managed. With reference to the Stonio 
tunnel, the emergency teams intervened in 2 min from the moment of activation while the total event lasted about $56 \mathrm{~min}$. In this case closure of the tunnel resulted in 14,371 vehicles to be managed (impact on the road system). In both cases the prompt intervention of the emergency teams allowed to effectively control and extinguish the fire.

\section{REFERENCES}

[1] Senato della Repubblica Italiana, Relazione concernente lo stato di attuazione degli interventi relative all'adeguamento delle gallerie stradali della Rete Transeuropea, Ministero delle Infrastrutture e dei Trasporti, 2013.

[2] Borghetti, F., Derudi, M., Gandini, P., Frassoldati, A. \& Tavelli, S., Safety in road tunnels. DOI: 10.1007/978-3-319-49517-0 1, 2017.

[3] Król, A. \& Król, M., Numerical investigation on fire accident and evacuation in a urban tunnel for different traffic conditions. Tunnelling and Underground Space Technology. DOI: 10.1016/j.tust.2020.103751, 2021.

[4] European Commission, Directive 2004/54/EC of the European Parliament and of the Council on Minimum Safety Requirements for Tunnels in the Trans-European Road Network 2004, Brussels, 2004.

[5] Beard, A. \& Carvel, R., The Handbook of Tunnel Fire Safety, Thomas Telford Publishing, 2005.

[6] PIARC, Technical Committee 3.3 Road Tunnel Operation. Experience with significant incidents in road tunnels, 2016R35EN, ISBN 978-2-84060-444-0, 2017.

[7] Bjørnsen, G. \& Njå, O., Competence constraints for fire and rescue personnel involved in tunnel fire safety as part of the tunnels' risk acceptability. Proceedings of the 30th European Safety and Reliability Conference and the 15th Probabilistic Safety Assessment and Management Conference, ISBN: 978-981-14-8593-0, 2020.

[8] Bosco, D., Lovreglio, R., Frassoldati, A., Derudi, M. \& Borghetti, F., Queue formation and evacuation modelling in road tunnels during fires. Chemical Engineering Transactions, 67, pp. 805-810, 2018. DOI: 10.3303/CET1867135.

[9] Nævestad, T. \& Meyer, S., A survey of vehicle fires in Norwegian road tunnels 2008 2011. Tunnelling and Underground Space Technology, 41(1), pp. 104-112, 2014. DOI: 10.1016/j.tust.2013.12.001.

[10] Borghetti, F., Cerean, P., Derudi, M. \& Frassoldati, A., Road tunnels risk analysis, 2019. DOI: 10.1007/978-3-030-00569-6_1.

[11] Nussbaumer, C., Comparative analysis of safety in tunnels. Austrian Road Safety Board, Young Researchers Seminar 2007, Brno, 2007.

[12] Caliendo, C. \& De Guglielmo, M.L., Accident rates in road tunnels and social costs evaluation. SIIV - 5 International Congress - Sustainability of Road Infrastructures. Procedia-Social and Behavioral Sciences, 53, pp. 166-177, 2012.

[13] Bassan, S., Overview of traffic safety aspects and design in road tunnels. IATSS Research, 40(1), pp. 35-46, 2016. DOI: 10.1016/j.iatssr.2016.02.002.

[14] Mashimo, H., State of the road tunnel safety technology in Japan. Tunnelling and Underground Space Technology, 17(2), pp. 145-152, 2002.

DOI: 10.1016/S0886-7798(02)00017-2.

[15] Vuilleumier, F., Weatherill, A. \& Crausaz, B., Safety aspects of railway and road tunnel: Example of the Lötschberg railway tunnel and Mont-Blanc road tunnel. Tunnelling and Underground Space Technology, 17(2), pp. 153-158 2002.

DOI: 10.1016/S0886-7798(02)00018-4. 
[16] Caliendo, C., Ciambelli, P., De Guglielmo, M.L., Meo, M.G., Russo, P., Simulation of fire scenarios due to different vehicle types with and without traffic in a bi-directional road tunnel. Tunnelling and Underground Space Technology, 37, pp. 22-36, 2013. DOI: 10.1016/j.tust.2013.03.004.

[17] Gehandler, J., Road tunnel fire safety and risk: A review. Fire Sci. Rev., 4(1), pp. 127, 2015. DOI: 10.1186/s40038-015-0006-6.

[18] Haule, H.J., Sando, T., Lentz, R., Chuan, C. \& Alluri, P., Evaluating the impact and clearance duration of freeway incidents. International Journal of Transportation Science and Technology, 8(1), pp. 13-24, 2019. DOI: 10.1016/j.ijtst.2018.06.005.

[19] Reggiani, A., Network resilience for transport security: Some methodological considerations. Transport Policy, pp. 63-68, 2013.

[20] Mattsson, L. \& Jenelius, E., Vulnerability and resilience of transport systems: A discussion of recent research. Transportation Research Part A: Policy and Practice, pp. 16-34, 2015.

[21] Carlson, J.L., Haffenden, R.A., Bassett, G.W., Buehring, W.A., Collins III, M.J., Folga, S.M., Petit, F.D., Phillips, J.A., Verner, D.R. \& Whitfield, R.G., Resilience: Theory and application, 2012. DOI: 10.2172/1044521.

[22] Ayyub, B.M., Systems resilience for multi-hazard environments: Definition, metrics, and valuation for decision making. Risk Analysis, 34(2)2, pp. 340-355, 2013.

DOI: 10.1111/risa.12093.

[23] Borghetti, F., Petrenj, B., Trucco, P., Calabrese, V., Ponti, M. \& Marchionni, G., Multilevel approach to assessing the resilience of road network infrastructure. International Journal of Critical Infrastructures, in press.

[24] Kim, H.K., Lönnermark, A. \& Ingason, H., Effective firefighting operations in road tunnels. SP Technical Research Institute of Sweden: Sweden, 2010.

[25] Chen, F., Chien, S., Lee, Y., Lin, C. \& Sie, H., The integrated strategies for fire safety of long road tunnels in Taiwan. Paper presented at the Procedia Engineering, 62, pp. 36-45, 2013. DOI: 10.1016/j.proeng.2013.08.042.

[26] Rhodes, N. \& MacDonald, M., FIT-European thematic network fire in tunnels, Fire response management (Technical Report Part 3), Brussels, Belgium, 2005.

[27] Borghetti, F., Derudi, M., Frassoldati, A., Lai, I. \& Trinchini, C., Tunnel risk analysis: A quantitative evaluation of the effectiveness of emergency teams inside the A24 and A25 motorway tunnels. Chemical Engineering Transactions, 82, pp. 277-282, 2020. DOI: $10.3303 /$ CET2082047.

[28] Caliendo, C., Genovese, G. \& Russo, I., A numerical study for assessing the risk reduction using an emergency vehicle equipped with a micronized water system for contrasting the fire growth phase in road tunnels. Applied Sciences (Switzerland), 11(11), 2021. DOI: 10.3390/app11115248.

[29] Amer, A., Roberts, E., Mangar, U., Kraft, W.H., Wanat, J.T., Cusolito, P.C., Hogan, J.R. \& Zhao, X., Traffic Incident Management: Gap Analysis Primer. Federal Highway Administration, 2015. 